\title{
PENDIDIKAN KARAKTER DALAM LONTAR TUTUR SILAKRAMANING AGURON-GURON
}

\author{
Oleh \\ Ni Made Sukerni \\ Dosen Pendidikan Agama IHDN Denpasar
}

\begin{abstract}
ABSTRAK
Pendidikan karakter mulai dinomor satukan oleh pemerintah, sebab perkembangan sosial politik, pendidikan dan kebangsaan sekarang ini memang cenderung menegaskan pendidikan karakter bangsa. Maraknya perilaku anarkis, tawuran antar warga, penyalahgunaan narkoba dan penyimpangan nilai-nilai karakter bangsa lainnya menunjukan indikasi adanya masalah akut dalam pembangunan karakter bangsa. Lontar Tutur Silakramaning Aguron-Guron merupakan salah satu sumber agama yang dijadikan sebagai pedoman dasar sebagai pembentukan karakter yang berlandaskan pada ajaran Tri Kaya Parisudh yang merupakan pondasi dalam membangun karakter anak yang dimulai dari pikiran.
\end{abstract}

\section{Kata Kunci : Pendidikan Karakter, Lontar Tutur Silakramaning Aguron-Guron}

\section{ABSTRACT}

Character education began under-united by the government, for political and social development, education and nationality nowadays, it tends to confirm the nation's character education. The rise of anarchic behavior, fighting between residents, drug abuse and perversion of character values of other nations showed indications of acute problems in the development of the nation's character. Lontar Tutur Silakramaning Aguron-Guron is one source of religion that serve as basic guidelines as the formation of character that is based on the teachings of Tri Kaya Parisudh which is the foundation to build the character of children who started from the mind.

Keywords : Character Education, Speech Lontar Silakramaning Aguron-Guron

\section{PENDAHULUAN}

Sistem Nilai yang perlu dipahami untuk dapat disumbangkan kepada masyarakat luas diantaranya adalah sistem nilai yang diajarkan oleh ajaran Agama, dalam hal ini yang dimaksudkan adalah ajaran Agama Hindu. Sekian banyaknya sistem nilai yang diajarkan dalam Agama Hindu adalah "kerja" yang dalam istilah Agamanya dikenal dengan "karma" (Singer, 2015:3). Karma adalah kerja, perbuatan, kegiatan, action dapat bersifat formal maupun physical, atau kejiwaan adalah aktivitas berpikir, menghayal dan merenung. Memandang kerja atau kegiatan pisik sebagai persembahan merupakan pandangan positif yang dapat dipertahankan konsepnya. Setiap perbuatan atau kerja dipersembahkan dengan sendirinya akan terlebih dahulu membawa kita kesuatu usaha untuk memahami bahwa persembahan dimaksud adalah persembahan yang tidak sia-sia, untuk itu kita harus mengetahui tentang "Dia" yang tiada lain adalah Ida Sang Hyang Widhi Wasa atau Tuhan Yang Maha Esa. Agar segala perbuatan, 
kerja dan kegiatan kita dapat mempunyai nilai positif bagi kehidupan umat manusia yang perlu diperhatikan terlebih dahulu adalah pola dasar yang mempengaruhi sikap hidup atau tingkah laku, yaitu Karakter.

Pendidikan karakter siswa dapat dibentuk melalui pendidikan, baik pendidikan formal maupun non formal. pembentukan karakter bisa dilakukan sejak anak itu masih berusia dini, seperti teori Tabularasa (John Locke) bahwa anak tersebut diibaratkan kertas putih. Anak yang baru lahir dapat diibaratkan seperti kertas putih yang belum ditulisi, disinillah pentingnnya seorang penulis yang mampu menulis kertas putih yang kosong tersebut dengan tulisan yang penuh dengan nilainilai luhur dan penanaman nilai pendidikan karakter yang akan mampu membentuk kepribadian anak ketika anak tumbuh dewasa, sehingga dimasa mudanya ketika anak mendapatkan lingkungan pergaulan yang bebas anak tidak merasa goyah sebab dalam dirinya telah tertanam ajaran kedisiplinan, jujur, dan tanggung jawab. Pendidikan juga mengajarkan tentang ilmu pengetahuan intelektual yang seharusnya juga didapatkan, diperdalam, dipahami, kemudian diamalkan, diabadikan sehingga tercapai keseimbangan antara pengetahuan spiritual dengan intelektual. Jika kedua hal tersebut tidak seimbang akan menimbulkan kegoncangan hidup. Dalam kekawin Ramaya hal ini digambarkan dengan sangat indah sebagai berikut : "Brahma Ksatriya padulur, jatinya paras paro sarppa naya, wiku tan panata ya hilang, tanpa wiku kanang ratu wisirna". Artinya: Brahma dan ksatrya selalu bersepakat, sesungguhnya, semestinya selalu saling membantu. Para pendeta tanpa didampingi oleh raja (Pemerintahan), akan kacau, begitu juga kalau pemerintahan tanpa didampingi oleh para pendeta (atau pengetahuan spiritual) juga akan mengalami kehancuran (Dinas Pendidikan dan Kebudayaan Provinsi Daerah Tingkat 1 Bali, 1986:11).

\section{PEMBAHASAN \\ Sinopsis Lontar Tutur Silakramaning Aguron-Guron}

Teks Lontar Tutur Silakramaning AguronGuron adalah Lontar yang membahas tentang aturan-aturan atau batasan-batasan yang boleh dilakukan seorang siswa serta yang tidak boleh dilakukan oleh seorang siswa. Lontar Tutur Silakramaning Aguron-Guron ini berisi petunjuk-petunjuk atau nasehatnasehat tentang bagaimana kewajiban dan tata krama seorang siswa (murid) dalam berguru (Silakramaning Aguron-Guron). Siswa yang dimaksudkan disini adalah siswa yang kerohanian atau calon pendeta yang hendak menerjunkan diri dalam hidup keagamaan. Seorang siswa yang menuntut ilmu tidaklah boleh berbohong terhadap guru, tidak membantah guru, tidak menyela perkataan guru, tidak memerintah guru, tidak memaki guru, tidak merebahkan badan dihadapan guru, dan tidak berkata sambil membelakangi guru, begitu pula pada istri guru. seorang siswa tidak boleh memberikan makanan sisa kepada guru dan istri guru serta jangan mencuri atau menggelapkan (milik guru), karena hal ini akan mengantar orang pada dosa, sedangkan sedikit mengantar orang pada kebaikan. Bila siswa yang tidak hormat pada orang banyak, oleh karena tidak tau itulah dosa (wiku) yang tersesat. Wiku demikian disebut "Wikayayanilibaken rat" (wiku yang mencurangi masyarakat), sudah tentu badannya akan mengalami penderitaan yang besar. Wiku yang berhati jahat (mengurusuk), pekerjaannya mengajarkan ilmu pengetahuan dan dharma pada suatu tempat yang dilewatinya dengan tujuan agar masyarakat mempersembahkan sesuatu kepadanya, hal ini sama dengan mengambil milik orang lain. Dosa dari perbuatannya tidak dapat dilihat, mengambil makanan dan ia sangat senang dihormati oleh masyarakat, memanasmanasi, mengampuni dan memperdaya orang bodoh, memukul dengan keras, bila demikian dosalah yang akan ditemukannya. perilaku 
yang demikian tidaklah layak bagi seorang siswa karena perilaku demikian amatlah besar dosanya. Sepatutnya hubungan seorang guru dan siswa adalah harus memegang teguh kebenaran, tidak menolak perintah guru. Apabila menyimpang maka guru akan turut berdosa. Guru mengajarkan yang baik tetapi murid tidak berpegang teguh pada kebenaran dan menolak ajaran guru, murid yang demikian sangatlah besar dosanya, karena antara yang memberi dan yang menerima sama dosa dan surganya. Guru yang memaki siswa dengan tidak senonoh, sedangkan siswa yang berpegang teguh pada kebenaran (tidak bersalah) maka berdosalah guru yang demikian. Bila siswa dalam menuntut ilmu memiliki kekeliruan patutlah sang guru memperingati siswa tersebut, kemarahan seorang guru diibaratkan seperti batu kering kejatuhan air, airnya akan segera mengering.

Demikianlah sepatutnya seorang guru bertindak, dan bila kesalahan dan kekeliruan yang dilakukan terus menerus walaupun telah diberikan teguran dan nasehat namun seorang siswa tidak mendengarkan dan sanak saudarapun tidak dapat menasehatinya lagi maka patutlah siswa yang seperti itu dikeluarkan, karena sangatlah besar dosa siswa yang demikian. Seorang siswa yang sedang menuntut ilmu membenci siswa lain, menyakiti siswa lain dan menjalankan ilmu hitam untuk menyakiti, sudah tentu siswa tersebut akan menjadi dasar neraka bagi orang yang disakiti tersebut.

Adapun orang yang telah memakai Bawa jika telah memiliki seorang murid berhak memberikan bawa kepada murid yang telah berhak memakai bawa, jika tidak akan berdosa. Dosa orang yang memberikan bawa kepada murid yang belum berhak memakai bawa sama adanya. Dalam Lontar Tutur Silakramaning Aguron-Guron selanjutnya membahas mengenai aturan kehidupan sehari-hari, baik dalam hal berpakaian, berperilaku dan berpikir. Maksudnya janganlah memberikan ilmu pengetahuan yang baru pada orang yang pikirannya masih kotor. Demikianlah nasehat guru bahwa orang yang terlepas dari nama, bawa, busana apalagi dengan dukuh. Semua itu tidak dapat membersihkan sebab kekuatan harus dibenarkan oleh budi, budi dibenarkan oleh hati (ambek), tingkah laku dan perbuatan dibenarkan oleh pengetahuan yang benar.

Budi tersebut tidaklah kekal, hati tidaklah pasti, ucapan tidaklah jujur, mencela semua yang bisa berjalan, merebut tempat orang, dosanya tidak terlihat, sangat senang hatinya jika dihormati banyak orang. Semua dapat terjadi seperti orang yang melakukan perjalanan. Seorang siswa harus dapat membekali dirinya dengan ilmu pengetahuan agar tidak tergoyahkan dan tidak tersesat. Harus selalu waspada, jangan tidak mendengarkan nasehat, jangan tenggelam dalam asmara cinta, jangan melibatkan diri pada perbuatan yang tidak terpuji dan sebagai siswa harus dapat berpegang teguh pada jalan kebenaran (Dharma). Dalam mencari kebenaran bagi seorang siswa hendaknya mencari kebenaran tersebut pada keluarga atau guru yang benar-benar sempurna perilakunya. Dalam Lontar Tutur Silakramaning AguronGuron menjelaskan bahwa yang tidak patut dijadikan guru adalah orang yang buta huruf, cacat tubuh dan himpoten, sebabnya tidak patut dijadikan guru, karena terlair dari neraka.

Lontar Tutur Silakramaning AguronGuron menjelaskan tiga perincian sebagai perwujudan Sang Hyang Dharma. Tiga hal perincian tersebut adalah Sang Hyang Tri Kaya Parisudha, yang dianggap emas (mastatur) tidak lain adalah perilaku, ucapan yang baik dan pikiran yang jernih dan cemerlang yang merupakan perwujudan Sang Hyang Dharma. Melaksanakan dan selalu mengingat perilaku yang benar, ucapan yang benar dan pikiran yang benar dan tidak ternodai oleh kotoran, kesemuanya itu lahir dari sesucian Sang Hyang Dharma. Bila ketiga hal tersebut telah dapat dilaksanakan maka diibaratkan nasi (waiwak tan pagogo), yang dihormati oleh sesamanya. 
Jika semua kemuliaan dari Sang Hyang Tri kaya Parisudha telah dilaksanakan maka semua kemuliaan akan didapatkan, karenanya perhatikanlah Sang Hyang Tri Kaya Parisudha. Seorang siswa yang menuntut ilmu harus demikian kata sang pendeta, karena ia adalah tempat untuk menanyakan yang baik dan buruk, kata-kata yang tidak patut adalah kata-kata yang jelek sedangkan kata-kata yang baik adalah kata-kata yang menyenangkan. Kemudian ada yang disebut Sang Hyang Dasasila, Sang Hyang Dasasila merupakan tempat untuk mempertanyakan baik buruknya perilaku, ucapan dan pikiran. Kesepuluh Indriya atau Dasasila itu adalah sebagai berikut: Caksuindriya, Srotendriya, Granendriya, Wakindriya, Jihwendriya, Panindriya, Padendriya, Paywindriya, Pastendriya dan Wakindriya. Kesepuluh organ yang ada dalam tubuh yang memiliki fungsi masing-masing haruslah dapat dikendalikan dan digunakan dengan baik. Siswa yang baik haruslah dapat mengendalikan dirinya agar dapat bertingkah laku yang berpedoman pada ajaran Sang Hyang Tri Kaya Parisudha dan Sang Hyang Dassila agar dapat membentuk karakter yang mulia dalam diri dan dapat menyucikan pikiran. Dengan berpedoman pada ajaran Sang Hyang Tri Kaya Parisudha Dan ajaran Sang Hyang Dasasila dapat menghindari diri dari musuh yang ada didalam dan diluar diri, dapat mengekang hawa nafsu, dan pengaruh Sad Ripu, Sad Atatayi dan Sapta Timira yang merupakan musuh dalam diri manusia. Selalu mengingat dan mengamalkan ajaran Tri Kaya Parisudha akan dapat mengarahkan pikiran pada kesecian, sehingga timbul kata-kata yang manis, perbuatan yang terpuji dan keinginan yang timbul dapat dikekang.

\section{Struktur Teks Lontar Tutur Silakramaning Aguron-Guron}

Usaha untuk melakukan penelitian objek yang akan diteliti harus ditetapkan terlebih dahulu, tidak ada penelitian yang dilakukan tanpa objek. Berkaitan dengan pernyataan tersebut diatas maka, objek penelitian bisa berupa simbol verbal dan nonverbal. Simbol verbal berupa bahasa verbal melalui ujaran, kalimat, pilihan kata dan dialek. Sedangkan bahasa nonverbal berupa ekspresi, wajah, gerakan tubuh tubuh, pakaian, intonasi suara (Engkus Kuswarno, 2009:124). Penelitian ini penggunakan objek penelitian berupa teks Lontar Tutur Silakramaning Aguron-Guron. Teks Tutur Silakramaning Aguron-Guron adalah sebuah teks yang terdiri dari simbol verbal berupa bahasa verbal, berupa kalimatkalimat verbal, yang perlu diketahui ajaran yang terdapat didalamnya. Teks Lontar Tutur Silakramaning Aguron-Guron sebagai objek penelitian akan digambarkan secara umum tentang keberadaan naskah itu seperti tentang manggala, korpus, dan tema tertentu yang terdapat didalam naskah tersebut.

Struktur merupakan lebih dari sekedar unsur-unsur dan totalitasnya, struktur dalam karya sastra lebih dari sekedar pemahaman bahasa sebagai medium, dan bukan sekedar penjumlahan bentuk dan isinya. Namun, struktur merupakan antar hubungan dengan kualitas energitas unsur (Kutha Ratna, 2012:76). Mengacu pada Teew (1994:110) menjelaskan bahwa struktur merupakan unsur-unsur seperti mata rantai yang menghubungkan unsur satu dengan unsur yang lain sehingga terbentuk menjadi karya sastra. Struktur juga disebut keterhubungan bagian cerita sehingga menjadi cerita yang utuh dalam sebuah karya sastra. Dalam struktur teks Tutur Silakramaning AguronGuron akan dibahas mengenai struktur formal atas teks.

\section{Struktur Formal Teks Tutur Silakramaning Aguron-Guron}

Menganalisis struktur teks Lontar Tutur Silakramaning Aguron-Guron, peneliti menggunakan teori Strukturalisme yang diajukan oleh Saussure yang diadaptasikan dengan pandangan yang ditujukan oleh 
Teew (1984:155) menjelaskan bahwa prinsip structural dijadikan pedoman, karena pedoman analisis structural bertujuan membongkar dan memaparkan secara cermat bagian-bagian teks sehingga menemukan makna konteks dari isi teks. Namun, analisis ini tidak sepenuhnya menelaah kaitannya dengan kajian sastra, tetapi memandang teks Silakramaning Aguron-Guron sebagai ragam tutur, yakni dengan sebuah sastra tutur dengan bahasa sebagai mediumnya. Dalam hal tersebut, Teew membedakan struktur menjadi dua bagian yaitu: 1) struktur formal yang meliputi manggala, korpus, dan bahasa teks; 2) struktur naratif yang meliputi yang meliputi tema dan aspek tutur. Penjabaran tersebut akan dijadikan acuan dalam mengkaji struktur teks Tutur Silakramaning Aguron-Guron.

\section{Struktur Naratif Teks Lontar Tutur Silakramaning Aguron-Guron}

Merujuk pada uraian dalam teori structural sastra, bahwa setiap karya sastra terdapat dua kategori struktur sastra yakni struktur formal dan struktur naratif. Sebagaimana Teeuw (1984:156) menjelaskan bahwa structural sastra memandang teks sastra dari dua struktur ekstrinsik, yaitu forma dan naratif, dan khusus dalam struktur naratif, teks dapat dilihat dari tema sentral teks serta aspek tutur teks. Berdasarkan pandangan teori tersebut, maka teks Tutur Silakramaning Aguron-Guron dari aspek struktur naratif dapat dilihat dari dua aspek yaitu tema teks dan struktur teks

\section{Ajaran Karakter Hindu Dalam Lontar Tutur Silakramaning Aguron-Guron}

Karakter artinya perilaku yang baik, yang membedakannya dari "tabiat" yang dimaknai dengan perilaku yang buruk. Karakter merupakan kumpulan dari tingkah laku yang baik dari seorang anak manusia, tingkah laku ini merupakan perwujudan dari kesadaran menjalankan peran, fungsi dan tugasnya mengemban amanah atau tanggung jawab (Nashir, 2013:10). Menurut Kamendiknas,
Karakter adalah watak, tabiat, akhlak atau kepribadian seseorang yang terbentuk dari hasil internalisasi berbagai kebajikan (Virtues) yang diyakini dan digunakan sebagai landasan untuk cara pandang berpikir, bersikap dan bertindak. Kebajikan terdiri atas sejumlah nilai, moral dan norma seperti: jujur, berani bertindak, dapat dipercaya dan hormat kepada orang lain.

Menurut Kamus Besar Bahasa Indonesia, ajaran adalah segala sesuatu yang diajarkan, segalah sesuatu yang dinasihatkan, petuah dan petunjuk. Jadi Ajaran Karakter Hindu adalah petuah atau petunjuk yang diajarkan untuk bertingkah laku, bertindak yang dilakukan berpedoman pada ajaran Veda yang merupakan kitab suci Agama Hindu dan sebagai tuntunan hidup semua manusia. karakter Hindu merupakan tindakan atau perilaku yang dilakukan sesuai dengan ajaran Agama Hindu, yang dapat membentuk manusia untuk menjadi yang lebih baik.

\section{Ajaran Tat Twam Asi}

Tat Twam Asi adalah ajaran kesusilaan tanpa batas yang merupakan filsafat Agama Hindu. Ajaran Tat Twam Asi dinyatakan identik dengan sila perikemanusiaan dalam Pancasila. Dinyatakan pula bila dicermati secara sungguh-sungguh, konsepsi sila perikemanusiaan dalam pancasila merupakan realisasi ajaran Tat Twam Asi yang terdapat dalam kitab suci Veda. Dengan demikian dapat dikatakan bahwa menghayati dan mengamalkan Ajaran Pancasila sama artinya dengan melaksanakan Ajaran Veda, karena maksud yang terkandung dalam Tat Twam Asi yakni "Ia adalah Kamu, Saya adalah kamu dan semua mahkluk adalah sama". Karena itu jika menolong orang, maka berarti kita telah menolong diri sendiri (Sudirga dkk, 2004:106). Selanjutnya dijelaskan pula bahwa Tat Twam Asi merupakan ajaran moral yang bernafaskan Agama Hindu, yang wujud nyatanya dapat dilihat dari kehidupan masyarakat sehari-hari, serta perilaku 
keseharian dari padanya. Ajaran Tat Twam Asi dapat dilaksanakan dalam kehidupan sehari-hari secara sungguh-sungguh dan menyeluruh, maka kehidupan masyarakat akan menjadi harmonis, saling menolong, saling menghargai dan saling menghormati, sehingga keadaan umat manusia akan menjadi aman dan damai. Karena Ajaran Tat Twam Asi merupakan pedoman dasar ajaran Susila atau etika Agama Hindu (Sukartha dkk, 2002:67) yang dijadikan pedoman dalam pelaksanaan hidup sehari-hari (Suhardana, 2010:17).

Tat Twam Asi termasuk dalam Samanya Dharmasastra, yaitu Etika atau Susila Agama Hindu yang berlaku umum atau universal dan dilaksanakan dalam kehidupan sehari-hari. Etika atau Susila yang merupakan unsur kedua dari kerangka dasar Agama Hindu (TatwaSusila-Upacara), sering juga disebut sebagai Dharmasastra. Dharma artinya menuntun atau membimbing, juga berarti hukum yang mengatur hak dan kewajiban manusia. Sedangkan sastra berarti ilmu pengetahuan. Dengan demikian Dharmasastra atau etika dapat diartikan sebagai pedoman atau hukum yang menuntut manusia dalam kehidupan bermasyarakat dan kehidupan social lainnya. Tanpa pedoman yang jelas untuk menuntun masyarakat dalam kehidupan sehari-harinya, boleh jadi akan mudah sekali timbul kekacauan (Nala cs, 1991:137).

Menurut Sukartha dkk (2002:67) Tat Twam Asi dinyatakan berasal dari bahasa Sanskerta sebagaimana yang tertuang dalam Chandogya Upanisad. Dijelaskan bahwa kata Tat berarti "Itu" atau "Dia," Twam berarti "Engkau" atau "Kamu" dan Asi berarti "adalah"

Tat Twam Asi pada dasarnya adalah Ajaran Kasih Sayang Terhadap sesama Mahkluk Ciptaan Tuhan. Dengan pengertian "Saya adalah Kamu" atau "Kamu adalah Saya", jiwaku adalah jiwamu," maka ajaran Tat Twam Asi merupakan ajaran persahabatan atau persaudaraan yang harmonis antara keluarga besar dunia, dengan tujuan dapat tercapainya kerukunan dan ketertiban dalam masyarakat.

\section{Ajaran Tri Kaya Parisudha}

Ajaran Tri Kaya Parisudha merupakan ajaran yang menyangkut tentang pendidikan karakter dalam Agama Hindu yaitu Manacika (berpikir yang baik), Wacika (berkata yang baik) dan Kayika (berbuat yang baik). Tri Kaya Parisudha merupakan salah satu konsep yang mempunyai makna mendalam dikalangan umat Hindu, dalam urusan budi pekerti. Konsep yang bersifat Uneversal ini mengajak kita agar selalu berpikir yang baik (Manacika), berkata-kata atau berbicara yang baik (wacika) dan berbuat yang baik (Kayika) yang dapat dipelihara dengan Karma Patha yaitu pengendalian. Dengan akal atau rasio yang dikarunia Tuhan kepada seluruh umat manusia, maka harus dapat mengendalikan tingkah laku dan perkataan melalui analisa yang logis tentang yang baik dan yang tidak baik. Justru dalam membedakan antara yang baik, yang tidak benar atau buruk atau jahat itulah letak kelebihan manusia dari mahkluk lainnya.

ITri Kaya Parisudha adalah landasan etik yang tertinggi dari ajaran Tata Susila Hindu yang tumbuh dari Tri Pramana. Idep atau Pikiran akan terproyeksikan dalam Manacika, yang merupakan permulaan atau asal mula dari timbulnya Sabda. Sabda terproyeksi dalam manacika. Kalau Manacika dan Wacika telah terwujud maka akan menjadi lengkap kalau diikuti bayu atau Kayika.

Lontar Tutur Silakramaning AguronGuron menjelaskan Ajaran Sang Hyang Tri kaya Parisudha dan Sang Hyang Dasasila yang dijadikan pedoman atau dasar dalam membentuk perilaku dan karakter yang baik pada diri siswa dan pada setiap orang, sebab Tri Kaya Parisudha merupakan landasan tertinggi dari ajaran Tata Susila Hindu yang tumbuh dari Tri Pramana Yaitu Bayu, Sabda dan Idep. Idep atau pikiran akan terproyeksikan dalam manacika, yang merupakan permulaan atau asal muladari timbulnya sabda. Sabda terproyeksi dalam manacika, kalau manacika dan wacika telah terwujud maka akan menjadi 
lengkap kalau diikuti oleh bayu atau kayika (Singer, 2015:105).

\section{Ajaran Dasasila}

Peranan Tat Twam Asi, Tri Kaya Parisudha dan Dasasila sebagai landasan pembentukan karakter sangatlah penting, sebab salah satu tata nilai yang merupakan Tata susila Hindu, Tri Kaya Parisudha merupakan sumber acuannya. Tri Kaya Parisudha merupakan bagian yang penting dalam implementasi seluruh kehidupan bermasyarakat, agar tercapai keharmonisan dalam kehidupan bermasyarakat untuk keberhasilan proses pendidikan penanaman konsep pembentukan karakter, diperlukan sistem kedisiplinan tinggi. Dengan ketidak disiplinan, apapun yang dikerjakan maka keberhasilannya akan diragukan. Dalam hal penanaman Konsep ajaran Tri kya Parisudha, perlu dipahami terlebih dahulu tentang aspek-aspek seperti, Idep, Sabda, Bayu; Pikiran, Perkataan dan perbuatan, dalam istilah hindunya Manacika, Wacika dan Kayika. Jika Tri Kaya Parisudha telah benar-benar melandasi pembentukan karakter, yang tercermin dalam kehidupan sehari-hari, akan menghasilkan individuindividu yang berkarakter, berbudhi luhur, yaitu individu-individu yang suka beryadnya, suka menolong, tidak kikir, karena merasa memiliki juga orang yang memerlukan tanpa mengharapkan balasan. Sabar dan rendah hati karena menganggap semua mahkluk adalah atma yang sama hidup dalam dirinya. maka apa yang dilakukan oleh orang lain, maka ditanggapi dengan sabar dan menghindarkan diri dari kesombongan, keangkuhan hingga tidak terjadi pertentangan, konflik dan permusuhan. hal seperti ini semua dapat terlaksana apabila terdapat disiplin diri, konsisten melaksanakan ajaran Tri Kaya Parisudha dan mampu menjalankan.

Nilai-Nilai Pendidikan Karakter Dalam Lontar Tutur Silakramaning Aguron-Guron

Pendidikan adalah suatu usaha sadar manusia untuk mendewasakan anak cara utuh. Pendidikan pada hakekatnya adalah pemanusiaan yang hanya dapat dilakukan oleh manusia itu sendiri. Manusia belajar dari sejak kecil, pendidikan dari kecil tersebut terus berlanjut sepanjang hayat (life long education) dalam upaya menemukan hakekat diri sendiri. Pendidikan merupakan suatu usaha untuk menyiapkan peserta didik menghadapi lingkungan hidup yang mengalami perubahan yang semakin pesat.

Pendidikan adalah usaha sadar dan tujuan untuk mengembangkan kualitas manusia. Sebagai suatu kegiatan yang sadar akan tujuan, maka dalam pelaksanaannya berada dalam suatu proses yang berkesinambungan dalam setiap jenis dan jenjang pendidikan. Semuanya berkaitan dalam suatu siste pendidikan yang integral. Jadi pendidikan sebagai suatu sistem, tidak lain dari suatu totalitas fungsional yang terarah pada sutu tujuan. Setiap sub sistem yang ada dalam sistem tersusun dan tidak dapat dipisahkan dari rangkaian unsur-unsur atau komponen-komponen yang berhubungan secara dinamis dalam suatu kesatuan. Memberikan kesempatan kepada setiap warga negara untuk mendapatkan pendidikan bermutu merupakan amanah dari sistem pendidikan nasional dan program pemerintah dalam meningkatkan kualitas sumber daya manusia, agar sejajar dengan manusia lainnya dimuka bumi (Tanu, 2011:1).

Terkait dengan pendapat diatas, bahwa peranan pendidikan sangat penting bagi manusia untuk meningkatkan kualitas hidup manusia itu sendiri. Kedudukan pendidikan sebagai sebuah instrument penting dalam meningkatkan potensi peserta didik agar menjadi generasi bangsa yang kuat dalam membentuk sumber daya manusianya (human resource). Dengan pendidikan, seorang anak pada nantinya akan menjadi manusiamanusia yang bermanfaat dan bermartabat, yaitu menjadi sosok manusia yang utuh ( $a$ fully functioning person). Salah satu bagian pendidikan karakter yang terdapat di Indonesia 
adalah menolong generasi muda memahami tradisi moral masyarakat Indonesia. Kita dapat menolong mereka memahami tradisi politik dan hukum yang berlaku di Indonesia (dan mengkritisinya). Kemudian, dilanjutkan dengan menggali konsep-konsep yang lebih abstrak seperti keadilan, kejujuran, kesopanan, benar dan salah, serta konsep-konsep yang menjadi landasan hukum suatu wilayah perlu juga digali kontribusi Agama-agama terhadap pengembangan tradisi moral, karena masyarakat Indonesia merupakan masyarakat religious.

Nilai-nilai luhur Pancasila banyak terdapat dalam karya sastra atau kesusastraan Indonesia. Sastra memiliki peranan penting dalam ragka pembentukan karakter peserta didik. Jadi, dengan mempelajari nilai-nilai karakter yang terkandung dalam karya sastra, merupakan sebuah proses pendidikan sebagai usaha mewariskan nilai-nilai luhur suatu bangsa yang bertujuan melahirkan generasi unggul secara intelektual dengan tetap memelihara kepribadian dan identitasnya sebagai bangsa. Pelestarian warisan karya sastra berupa teks, merupakan salah satu usaha untuk melestarikan kebudayaan Indonesia Khususnya di Bali agar tetap ajeg dan mempertahankan nilai-nilai luhur yang terdapat didalamnya. Salah satunilailuhuryang tersirat karya sastra adalah nilai pendidikan karakter. Terkait dengan hal tersebut dalam teks Tutur Silakramaning Aguron-guron yang merupakan karya sastra berbentuk teks yang terdapat nilai-nilai pendidikan karakter antara lain : Nilai Religius, Nilai Jujur, Nilai Disiplin, Nilai Toleransi, Nilai Demokratis, Nilai Beersahabat/komutatif, Nilai Cinta Damai, dan Nilai Tanggung Jawab.

\section{SIMPULAN}

1. Struktur teks Lontar Tutur Silakramaning Aguron-Guron membahas tentang 1) Struktur forma yang terdiri dari pembuka teks (manggala), korpus (isi keseluruhan dari naskah), dan bahasa yang digunakan; 2) Struktur naratif yang terdiri dari tema (inti dari teks Tutur Silakramaning Aguron-Guron) dan aspek tutur.

2. Ajaran karakter Hindu dalam teks Lontar Tutur Silakramaning Aguron-Guron, yaitu ajaran Tat Twam Asi, Sang Hyang Tri Kaya parisudha dan ajaran Sang Hyang Dasasila yang dijadikan pondasi dalam pembentukan karakter. Kedua ajaran tersebut merupakan ajaran yang menuntun seseorang dalam melakukan pengendalian agar tidak terjatuh atau terjerumus pada jalan yang salah, sebab bagian Tri Kaya Parisudha yang pertama yaitu manacika merupakan pusat atau sumber yang mengatur atau mengarahkan indriyaindriya yang lain untuk berbuat.

3. Nilai-Nilai pendidikan karakter yang terdapat dalam Teks Lontar Tutur Silakramaning Aguron-Guron yaitu : Nilai Religius (bersifat keagamaan), Nilai Jujur (tidak suka berbohong), Nilai Disiplin (taat akan peraturan/tata tertib), Nilai Toleransi (sikap menghormati/menghargai), Nilai Demokratis (sikap yang mengutamakan persamaan hak dan keajiban), Nilai Bersahabat/Komunikatif (tindakan yang memperlihatkan kasih sayang), Nilai Cinta Damai (sikap dan tindakan yang membuat orang lain merasa senang dan nyaman), Nilai Tanggung Jawab (sikap sadar akan apa yang dilakukan).

\section{DAFTAR PUSTAKA}

Adisusilo, Sutarjo. 2012. Pembelajaran Nilai Karakter Konstruktivisme dan VCT sebagai Inovasi Pendekatan Pembelajaran Afektif. Jakarta : Rajawali Press. 
Aunillah, Nurla Isna. 2011. Panduan Menerapkan Pendidikan Karakter Di Sekolah. Yogyakarta: Laksana.

Afifuddin. H, dan Beni Ahmad Saebani. 2009. Metodologi Penelitian Kualitatif. Bandung: Pustaka Setia.

Akbar, Ali Ibrahim. 2009. Karakter Kunci Sukses Kehidupan. Jakarta: Departemen Pendidikan Nasional.

Arikunto, Suharsini. 2000. Prosedur Penelitian suatu pendekatan praktek. Rineka Cipta : Yogyakarta.

Azwar, Saifuddin. 1999. Metodelogi Penelitian. Pustaka belajar: Yogyakarta.

Departemen Pendidikan Nasional. 2008. Kamus Besar Bahasa Indonesia Edisi Keempat. Jakarta. PT Gramedia Pustaka Utama.

Tagel, I Dewa Putu. 20015. Teologi Hindu Dalam Teks Siwagama dan Implementasinya di Kota Denpasar. Denpasar : Pasca Sarjana IHDN.

Elfindri, Dkk. 2012. Pendidikan karakter Kerangka, Metode dan Aplikasi untuk Pendidikan dan Profesional. Jakarta : badauose Media Jakarta.

Fathoni, H. Abdurrahmat, 2006.Metodologi Penelitian \& Teknik Penyusunan Skripsi. Rineka Cipta. Jakarta.

Gunawan, I Ketut. 2013. Implikasi Pendidikan Karakter dalam Upacara Panca Yadnya dalam Keluarga Hindu Di Kota Singaraja. Tesis (tidak diterbitkan). Program Pasca Sarjana IHDN Denpasar.

Gunawan. Heri. 2012. Pendidikan Karakter konsep dan Aplikasinya. Jakarta : Ghalia Indonesia.
Ihsan. H. Fuad. 2011. Dasar-dasar Kependidikan. Jakarta : Rineka Cipta.

Iqbal, Hasan. 2002. Metodelogi Penelitian dan Aplikasi. Jakarta : Ghalia Indonesia.

Jalaludin, H. 2007. Psikologi Agama. Jakarta : Raja Grafindo Persada.

Koesoema, Doni A. 2007. Pendidikan Karakter Strategi Mendidik Anak di Zaman Global. Jakarta: Grasindo.

Kadjeng, I Njoman d.k.k. 2014. Sarasamuccaya. Biro Kesra Setda Provinsi Bali.

Kutha Ratna, Nyoman.2010. Metodologi Penelitian Kajian budaya dan Ilmu social Humaniora Pada umumnya. Yogyakarta: Pustaka Pelajar.

Lickona, Thomas. 2013. Pendidikan Karakter panduan Lengkap Mendidikan Siswa menjadi Pintar dan Baik. Bandung : Nusa Media.

Moleong, Lexy. J. 2002. Metode Penelitian Kualitatif. Bandung: Remaja Rosdakarya. Bandung.

Mukajir, 1990. Metode Penelitian. Bandung: IKIP.

Muhajir, Neong. 1998. Metodelogi Penelitian Kualitatif. Yogyakarta : Rake Narbuko, Achmadi. 2008. Metodelogi penelitian. Jakarta : Bumi Akasa Sarasin.

Mulyana, Rohmat. 2011. Mengartikulasikan Pendidikan Nilai. Bandung: Alfabeta.

Mulyadi, Tude. 2014. Nilai Karakter Dalam Teks Bhagawan Dhomya. Denpasar: IHDN. 
Megawangi, Ratna. 2007. Semua berakar Pada Karakter "isu-isu Permasalahan pada bangsa”. Jakarta : Lembaga Penerbit Fakultas Ekonomi UI.

Nashir, Haeder. 2013. Pendidikan Karakter Berbasis Agama dan Kebudayaan. Yogyakarta : Multi Presindo.

Noor, Rohinah m. 2012. Mengembangkan Karakter Anak Secara Efektif di Sekolah dan di Rumah. Yogyakarta : PT Insan Madani, Anggota IKAPI.

Nala cs. Gusti Ngurah. 1991. Murddha Agama Hindu. Denpasar : Upada Sastra.

Pudja, Gede. 1999. Bhagawadgita (Panca Weda). Sirabaya : Paramita.

Punyatma, Oka. 1994. Cilakrama. Denpasar : Upada sastra.

Ritzer, George dan Douglas J. Goodman. 2011. Teori Sosiologi Modern. Jakarta : kencana.

Ridwan,. 2004. Metode Dan teknik Penyusunan Tesis. Alvabeta : Bandung.

Syuropati, Soebachman. 2012. 7 Teori Sastra Kontemporer \& 17 Tokohnya. Yogyakarta : IN AzNA Books.

Sriasih, Sang Ayu Putra, 2012. Kearifan Lokal dan pendidikan Karakter. Prosiding Konfrensi Internasional Budaya Daerah ke-2 (KIBD-II) Denpasar : Pustaka Lasaran bekerja sama dengan IKIP PGRI BALI dan IKADBUDI. 